\title{
Improving Learners' Oral Skills through Two Types of Role-play
}

\author{
Bokja Cho
}

\begin{abstract}
Role-play is commonly regarded as a useful activity for developing oral skills (Livingstone 1983; Maley 1987; Magos and Politi 2008). However, there is little research on different types of role-play and on its use in English for Occupational Purposes (EOP) contexts, which is what the present study seeks to redress. This study reports on research investigating the effectiveness of two types of role-play, SSRP (Semi-scripted Role-play) and SSRP-NSRP (Semi-scripted Role-play followed by Non-scripted Roleplay), in the teaching of Tourism English (TE) at a university in Korea. The study used an action research approach (Kemmis and McTaggart 1988) with the aim to improve TE learners' oral skills. In Study I students practised SSRP, while in Study II they engaged in SSRP-NSRP. The results of a two-way statistical test (ANOVA) show that there is a significant difference between the means of the pretests and post-tests of both Studies I and II.
\end{abstract}

\section{Introduction}

In the tourism industry, the importance of language skills is increasing and is being emphasised more than in any other business sector. The Korean Tourism Organization (KTO) reported that the number of international tourists visiting Korea climbed from 5.1 million in 2001 to 9.7 million in 2011. Now that the tourism industry has grown, together with the demand of Koreans' own overseas travel, it has definitely become one of the biggest growth industries in Korea. As the tourism industry expands, the demand for an adequate professional workforce is increasing, in particular the demand for people who have foreign-language skills is on the increase. The KTO conducted a survey in relation to the inconveniences foreign tourists had encountered during their stay in Korea and more than half of the foreign-tourist respondents selected 'language barrier' as creating the most inconvenience and this problem persists.

A good command of the English language enables tourism industry employees to communicate with their counterparts in the world and serve their clients better in the workplace. For example, it was revealed from studies conducted 
by Korean researchers (Choi 2006; Seong 2001) that Tourism English (TE) learners in Korea want to improve their English language, and ranked speaking skills as the most important.

Although a few years ago in Korea reading and listening skills prevailed in TE classes as well as in general English classes, the demands from employers and markets have changed this trend dramatically. As the majority of students want to work for leading companies in the tourism industry after graduation, the job market in the tourism industry is very competitive. Employers in the tourism industry do not just employ graduates who have studied Tourism Management but they require good English conversational skills which are tested through interviews conducted in English. Therefore, it is necessary to provide students with the required skills that they can exploit in the real situations that they can expect to face upon their university graduation. As a consequence, oral communication skills teaching in near-to-real situations is essential for most Tourism students. Min (2009) for example suggests that TE in Korea should be focused on practical use since it needs to be used directly in the workplace (EOP). Indeed, the syllabus for TE in Korea is geared toward the inclusion of conversation classes since employers in the tourism industry consider seamless oral communication skills to be one of the most important TE skills that graduates must have.

There are numerous reasons that make role-play suitable for teaching TE. Role-play is considered an ideal technique to encourage students to use real language (Maley \& Duff 1982; Livingstone 1983; Van Ments 1983; Maley 1987; Siskin \& Spinelli 1987; Magos \& Politi 2008). The characteristics of TE include limitation, predictability, and the use of technical terms, even though many of them overlap with general English. Many interactions occurring in the tourism industry can be routine. Typical routines in TE relate to staff responsibilities such as checking in/out, explaining the menu, dealing with any special requirements (e.g. smoking or non-smoking seats/rooms, available facilities, recommending tours), reservations for a table/seat/tour, and so on. The predictable nature of such interactions makes them suitable for practice in the form of a role-play. Role-play also provides an opportunity for students to acquire and practise specific terms or general English words that are particularly common in interactions in tourism. Furthermore, the advantage of role-play is that it can be adapted to different proficiency levels; as Tompkins (1998) argues, the way role-play is structured, assigned and employed, usually depends on the linguistic level of the class.

Another reason for adopting role-play is a practical one and is concerned with the size of classes at Anyang University (AU). Many conversation classes consist of question and answer sessions where the teacher does most of the talking with students individually. Using role-play makes it possible to increase students' talking time in large classes by engaging them in meaningful conversation practice among themselves.

Many teachers have used role-play in their classroom, but few have studied it as an educational practice. While the literature on role-play suggests there 
are various advantages to applying role-play in the language classroom, few studies have focused on the learners' perspectives regarding role-play. In addition, although there is some research on the use of role-play in ESP contexts (Sturtridge 1977; McDonough 1984), role-plays have not been studied specifically in the context of TE.

This study is part of a larger research project, which was an action research study of the effectiveness of two types of role-play in teaching English for tourism at a Korean university, but in this paper I only report one part. In terms of matching learners' proficiency and spoken English needs, this study provides responses to the following questions: Did the learners' oral skills improve through each year's role-play activities? If so, (a) to what extent did the learners' oral skills improve through SSRP and SSRP-NSRP and (b) did they improve more with SSRP-NSRP than with SSRP?

\section{Role-play in the English for Specific Purposes (ESP) Context}

In the ESP context, various task types such as information-gap tasks, language games, simulations and so on have been used to stimulate learners to practise their oral skills in the classroom. Many proponents of roleplay (e.g. Sturtridge 1977) claim that it can be used to not only simulate the sorts of communication tasks which learners are required to perform in the real world but also to encourage learners to take part in communication which involves personal experience and emotions. As a consequence, through role-play, learners will not only learn more about the communicative use of language in the L2 occupational reality, but will hopefully learn more about the settings/scenarios relevant to their occupational field (McDonough \& Shaw 1993: 217-8).

What, then, are the special reasons for using role-play in an ESP classroom? According to Maley (1987: 6), firstly, a wide variety of language experience can be brought into the classroom through role-play:

[...] the range of functions and structures, and the areas of vocabulary that can be introduced, go far beyond the limits of other pair or group activities, such as conversation or communication games.

Thus, through role-play, teachers can train ESP learners to develop the speaking skills for their target situations. For example, ESP students may be able to acquire conversational structures including openers, connectors, pre-closers and closers (Di Pietro 1982; Dörnyei and Thurrell 1994) which they will have to include in their interactions with, for example, customers or clients. In addition, learners can practise using certain conversational patterns, such as subtle rules determining who speaks and when, and for how long, which may enable them to take turns neatly and avoid overlap and simultaneous talk (Dörnyei and Thurrell 1994: 40). 
Secondly, role-play can put ESP learners in situations very like those in which they will actually be required to use specific forms of language. Littlewood (1981) assumes that realistic role-play is valuable because it replicates what students will do in real life. As in real-world communication, so in some forms of role-play, "they must negotiate the interaction itself as it unfolds" (Littlewood 1981: 56). Stern (1980: 85) also claims that the activity may help a student to extend his or her powers of communication by exploiting hitherto "untapped resources". Role-play presents students with the opportunity to use not only the linguistic skills that they have been learning but also such pragmatic abilities as they can master (Cunningsworth \& Horner 1985: 217), which means that role-play can be a stage for ESP learners to practise job-related skills required in the relevant professional industry.

Finally, by providing ESP learners with the opportunity both to practise the language they will encounter in their everyday life, and at the same time to experience a simulation of the real situation where they might use it, they may be better able to deal with similar situations outside the classroom. For example, even though students may have experience participating in role-play in the classroom, they may not have had real-life experience using the target language. Some probably will have never been in certain situations in their lives. Thus, preparation in the classroom will be essential in order for them to get used to both the new language and new situations they are likely to encounter. Others might have performed the situations through role-play many times in their L1 or they might have been in those situations in their work place. But there may still be many cultural differences apparent between the L1 and L2. In this study, both types of students described here were identified.

\section{Types of Role-play}

Role-play can be grouped into three types: fully scripted role-play (SRP), semi-scripted role-play (SSRP) and non-scripted role-play (NSRP).

In a fully SRP, every word is provided, and all the participants have to do is to read or memorise their lines (Harper-Whalen \& Morris 2005). This type involves interpreting the model dialogue in the textbook and the main function of the dialogue after all is to convey the meaning of language items in a memorable way (Byrne 1986). This type of role-play can be suitable for lower level proficiency students who may be unfamiliar with the context as the SRP type is highly structured.

The second type of role-play involves a model dialogue with some blanks and students may fill in the gaps with some appropriate words for their situation (Livingstone 1983). Thus learners can modify the original dialogue to some extent and create their own dialogue. This type of role-play can be classified as semi-controlled or SSRP as the teacher or textbook provides linguistic input, but learners should also determine the content based on a framework which provides the opportunity to create a realistic dialogue (Harper-Whalen \& Morris 2005). This SSRP type can be used for learners with upper-beginner to 
intermediate levels of proficiency, who are familiar with the basic procedures and want to move on to more complex tasks as SSRP is less structured and less controlled than SRP.

The third type of role-play is where students may be provided with cued dialogues (Holden 1981; Littlewood 1981; Dickson 1989), cues and information (Littlewood 1981; Livingstone 1983), or situations and goals (Littlewood 1981) in less structured and controlled activities, where students make up short dialogues based on the above cues, information or situations rather than simply filling in gaps (Pi-Chong 1990). Harper-Whalen \& Morris (2005: 3) classify this type of role-play as NSRP, and they argue that NSRP offers an excellent opportunity to use ideas or skills in context. Davies (1990: 94) points out that learners can draw on their thoughts and feelings, and generate language in their improvisations, creating people and relationships by acting out situations without a preconceived plan. NSRP can be applicable to for intermediate to advanced level learners as NSRP is freely structured and sometimes requires problem-solving skills.

In this study, the original role-play terms referred to above were modified and used in accordance with the role-play activities learners performed in the two separate experiments reported here, referred to as Study I and Study II. For Study I, SSRP was used: here learners were given a script in the book or material provided by the teacher, and then they created their own script. For Study II, a semi-scripted role-play was followed by a non-scripted role-play (SSRP-NSRP): here the first stage was exactly the same as that of Study I, but then in the second stage learners worked with 3-4 people in a small group and, during this stage, were provided with a prompt for a dialogue without a script.

\section{Research Design of the Studies}

\subsection{SSRP Learners (Study I) and SSRP-NSRP Learners (Study II)}

30 second year learners enrolled on my module for the first semester in 2005 (Study I - SSRP was used), and 36 second year learners enrolled on my module for the first semester in 2007 (Study II - SSRP-NSRP was used). The profiles of the two groups are virtually identical, showing that the two action research phases were executed on students who in classical research terms would be seen as samples from the same wider population. Both years' learners were upper-beginners and low intermediates in terms of their level of proficiency in English, averaging 22 years of age, with 6 years of formal English education, majoring in TE in AU in Korea. In order to identify the level of speaking and listening skills, the learners themselves checked their proficiency levels based on a performance scale from the Council of Europe framework translated into Korean and provided by the teacher with a needs analysis questionnaire. This was basically a self-rating by the students of their proficiency showing their English proficiency level was currently at approximately B1 level. The majority of learners gave themselves a rating of upper-beginner for their speaking 
skills, while all other skills, listening, reading and writing, were rated as lower-intermediate. This shows that learners feel speaking is their weakest skill compared with listening, reading and writing. This results from the fact that their English study during middle and high school focuses mainly on reading and grammar.

\subsection{Settings for Studies I and II}

Research studies I and II were conducted in a TE module taught in the Department of Tourism Management at AU which is a private university located in Anyang City, south of Seoul in Gyeonggi province in Korea.

The class met one day a week for a total of 3 hours during a 16-week semester. Most students who had registered for this module took the same subjects when they were first year students. These include English conversation, some subjects related to tourism theory and some liberal arts subjects. The TE module for TE majors, which is the locus of my research study, has the following objectives: (1) to develop students' spoken skills for communication in the tourism industry and (2) to enhance their confidence when they speak English. Hence it is exclusively oriented to speaking (and some inevitable listening).

I investigated the training needs and requirements identified by the training managers in the tourism industry for their employees, and identified graduates' (current employees') views about the language needs at their workplace by the Needs Analysis (NA) questionnaires in 2005. Both years' learners' background information, including their needs and wants, were surveyed by the NA questionnaires. The questions serve a combination of three types of analysis: a Present Situation Analysis (PSA), a Target Situation Analysis (TSA) based on learners' perceptions and an analysis of learners' preferred teaching style. A Mann Whitney Nonparametric test for two independent samples was used to determine whether there was a statistically significant difference between responses to the questions between SSRP learners and SSRP-NSRP learners.

The results for training managers', graduates' and learners' needs merge into one - improving speaking skill. Learners' preferred teaching method is role-play, and in the learners' preferences for aspects of group activities, they prefer working with the other people. Importantly, learners consider that role-play could be adequate for their level and helpful in learning TE.

Overall, these findings supported my decision to focus on role-play in our module since students should be in a situation where they must talk (Horwitz 1985: 205). Role-play will also help learners handle situations which they might face in the tourism industry and require communication skills (Magos \& Politi 2008). The findings also guided our implementation of role-play in selecting situations and topics carefully for TE learners. Role-play was considered to be beneficial for TE learners since they will be primarily in the situations where they should interact and deal with customers. It also helped me progressively in designing the initial action covered by this PhD study, SSRP and then thinking of a possible improvement for the second action, SSRP-NSRP. SSRP was adopted 
first in 2005 (Study I). In SSRP, the learners were asked to practise saying the dialogue in a unit in the textbook or from the teacher's material and to act it out with their partner. Then they were encouraged to reproduce it adequately and finally present the new version in front of the class. While I was conducting Study I, I discovered some failings and difficulties: learners worked with only one person and sometimes worked with the same person the following week. Learners wrote a script (dialogue) to present, so they memorised the dialogue.

Based on the problems with Study I, I decided to use SSRP-NSRP in a TE class to give the students experience similar to that of real-world situations in 2007 which forms the basis of Study II. In 2007, after the SSRP phase, the learners did not prepare a new version of the script, but rather in the NSRP phase they talked with a few different partners retrieving or making up what they said as they spoke spontaneously. In real life, an employee may deal with several different clients and may deal with different issues. Thus, the classroom sometimes became an airport, restaurant or hotel reception desk, and the learners all stood up and acted as if they were a real employee or client.

The aim of this study was to evaluate two different types of role-play, SSRP and SSRP-NSRP, while teaching TE to second year learners in AU, a Korean university.

\section{Instructional Interventions Researched in This Study}

\subsection{Plan of the SSRP and SSRP-NSRP Part of the Lesson}

To improve learners' communicative interaction skills, in 2005 role-play was adopted to teach TE as a main method, and both the SSRP and the SSRP-NSRP version tried subsequently involved three phases.

\subsection{The Pre-Role-Play Phase}

In the pre-role-play phase, information input (task, rules, background and technical data) and linguistic input (vocabulary commonly used, expressions and specific grammatical constructions) are given by the book, the teacher and sometimes the classmates who have experience in some situations. In the classroom described in this particular study, the learners were assigned the relevant words or expressions used for the role-play activity to study so that they could contribute to the role-play more effectively and have enough time to perform the role-play without wasting time getting bogged down by unknown words.

\subsection{During Role-Play Phase}

In this phase, both SSRP and SSRP-NSRP learners read out the script by playing a role as shown in the model dialogue, got used to the situation first, and studied the vocabulary items and expressions needed in the situation. Next, the SSRP 
sequence was described in detail. After that, SSRP learners made their own script. At this stage even though the teacher did not guide learners in writing down their own script, most learners wrote it out and corrected it instead of speaking it out loud. This is because they were not familiar with role-play in the class and not confident about their English. They were encouraged to expand the model dialogue (adding more questions and answers), or apply it to a new situation (e.g. learners could set up a new situation, different from the situation in the model dialogue), and make their own dialogue.

The interaction pattern in SSRP is the pairing shown in Figure 1, with different pairings in each class. For example once 'A' and 'B' play a role-play as employee and a client, A and B change their roles. In order to stop learners sitting with the same partner, the learners were all allocated their partner by drawing lots every week.

Table 1: Fig. 1. Single Channel Interactive Patterns

$$
\mathrm{A} \longrightarrow \mathrm{B} \quad \mathrm{B} \longrightarrow \mathrm{A}
$$

SSRP-NSRP learners also had adequate time to prepare themselves before they started, to think over the way they would organise their role and briefly rehearse between two people, A and B, for instance. During the rehearsal, they asked for help from their teacher or from any peers who had a higher linguistic level in the English language. As far as the interaction pattern is concerned in SSRP-NSRP, one person, for example learner 'A' becomes an employee, serves 3-4 different clients (B, C, D and E), and deals with each person. After A has dealt with B, C, D and E, it is B's turn to become an employee, and serves A, C, $\mathrm{D}$ and $\mathrm{E}$, and so forth, as shown below in Figure 2 and 3.

Table 2: Fig. 2. Multi Channel Interactive Patterns
$\mathrm{A} \rightarrow \mathrm{B}$
$\mathrm{B} \rightarrow \mathrm{A}$
$\mathrm{C} \rightarrow \mathrm{A}$
$A \rightarrow C$
$\mathrm{B} \rightarrow \mathrm{C}$
$\mathrm{C} \rightarrow \mathrm{B}$
$A \rightarrow D$
$\mathrm{B} \rightarrow \mathrm{D}$
$\mathrm{C} \rightarrow \mathrm{D}$
$A \rightarrow E$
$B \rightarrow E$
$\mathrm{C} \rightarrow \mathrm{E}$

In this case, each person who, for example, played the role of check-in staff served three different people who had a different background (e.g. business traveller or honeymoon tourist) and different kind of inquiry, and vice versa, and when the person was a client, he/she talked with three different check-in staff.

There are two key differences between the SSRP and SSRP-NSRP during- 


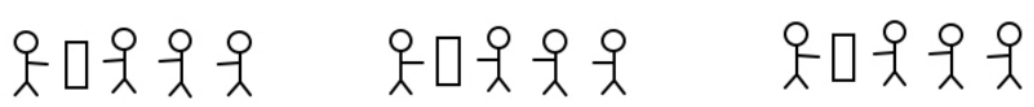
A1 B1 C1 D1
A2 $\quad$ B2 $\mathrm{C} 2$ D2
$\mathrm{A} 3$
B3 C3 D3

Figure 1: Fig. 3. SSRP-NSRP Layout

role-play phase: one is that in SSRP the role-play script was written down beforehand so players knew it before speaking and did not have to make anything up on the spot. However, in SSRP-NSRP, learners were given a scenario beforehand, which meant they could expect what was going to happen, but questions and answers from an employee and tourists (or clients) were not known fully to everyone in advance, because it was not written, and it was 'new' in that sense to the participants, like in real life. The other difference was that SSRP interaction occurred between two people only, which meant there was one scenario between two. On the other hand, in SSRP-NSRP, interactions took place among 3-5 different partners. This meant that SSRP-NSRP learners could be involved in a variety of interactions with different people in the same situation. This helped learners get used to dealing with situations and interaction sequences spontaneously, and practice the language they need in such a situation more naturally. Finally, while SSRP-NSRP learners recorded their dialogue at this stage, SSRP learners recorded only in their post role-play phase.

\subsection{Post-Role-Play Phase}

The post-role-play phase is the feedback stage. The learners got feedback both each other and the teacher. In this stage, the teacher could plan the language work which would most benefit the class as a whole, based on the observation of the role plays earlier. Students also could actively and freely say what they themselves wanted to communicate in certain situations but were unable to.

After practising their own dialogue, SSRP learners started recording their own script. While they recorded, each learner had to play both roles (he/she could be a receptionist once and a client next). However, in the 'post-role-play phase', different from SSRP learners, SSRP-NSRP learners did not record themselves, but rather, their audio recording had already been done in the 'during-role-play' phase at the same time as they performed their role-play with 3-5 different people. This change was made for Study II since some problems had been identified with SSRP learners' recording in Study I: first, SSRP learners did not want to record straight after practising, which delayed the next stage. Second, it was realised that if learners want to monitor themselves or get feedback on their performance, it is more valuable to use their raw dialogue rather than a performance after repetitive practice. Thus, when SSRP-NSRP learners role-played with each partner, they were required to record at the same time 
as they were talking so that learners and the teacher could have a realistic check on learners' current status. Thus, this intervention with SSRP-NSRP learners' recording is believed to yield more valid information to check learners' performance and progress for both pedagogical and research purposes than the SSRP learners' type of recording.

\subsection{Pre-/Post-test of Speaking: Role-Play Presentation}

To answer the research question objectively, role-play speaking tests (i.e. a direct test of the skill being taught) were administered to the learners enrolled in the module at the beginning and end of the module to assess the progress made by these students in developing their spoken English during this action research.

In both Studies I and II, weeks 4 and 15 were selected for testing learners' progress. The reason week 4 was selected instead of week 1 was that although a pre-test is usually conducted at the beginning of the course or before the intervention, I could not assess learners at the beginning of the course. Learners' spoken interaction basically requires some language knowledge and specific purpose content knowledge. Study I and Study II learners were not familiar with role-play in this $\mathrm{TE}$ class since they did not have role-play experience in other English classes, and they had not been previously assessed with a role-play based test. Thus, it was fair that learners were assessed after being given a general idea of role-play itself, and had received input on language and specific purpose content knowledge for a few weeks. Before trying out the tests, I consulted three lecturers who used to be managers in the hotel and tourism industry about the context and realism of the tasks.

Pre- and post-tests for Studies I and II were scored by two scorers, the researcher and a teacher who was a native English speaker. I averaged the scores of the two raters for each participant in both years and all results are based on these average scores. Two different English native speaker teachers were used for the two studies; both were teaching English in the same university. Before the assessment day, I showed these assessment criteria to my colleague, the other assessor, who checked whether he was familiar with the assessment criteria, and read through each category together. It is crucial that test scorers have a common understanding of how learner responses are scored in relation to the role-play scoring rubric.

As each pair started their role-play, the examiners marked their performance on the evaluation sheet as unobtrusively as possible. Learners were assessed for performance in five categories: 1) accent, 2) grammar, 3) vocabulary, 4) fluency and 5) comprehension. The assessment criteria were adopted from the FSI (Foreign Service Institute), each measured on a six-point scale (Barnwell 1987: 36). The scale ranges from no proficiency to native speaker ability. For the test rating for this study, it was decided that only five points of the scale would be used ( 1 being poor, through to 5 being excellent) instead of six, since learners' proficiency did not reach the advanced level (scale 6). 


\subsection{Study I and II Results: Pre-/Post-tests of Speaking}

Table 1 presents the results of the two-way ANOVA to check if there were any statistically significant differences between pre-test and post-test and between the two years' groups.

\begin{tabular}{|l|c|c|c|c|c|c|c|c|c|c|}
\hline \multirow{2}{*}{ Effect } & \multicolumn{2}{|l|}{ Vocabulary } & \multicolumn{2}{l|}{ Accent } & \multicolumn{2}{l|}{ Fluency } & \multicolumn{2}{l|}{ Comprehension } & \multicolumn{2}{l|}{ Grammar } \\
\cline { 2 - 11 } & $\mathrm{F}$ & $\mathrm{P}$ & $\mathrm{F}$ & $\mathrm{P}$ & $\mathrm{F}$ & $\mathrm{P}$ & $\mathrm{F}$ & $\mathrm{P}$ & $\mathrm{F}$ & $\mathrm{P}$ \\
\hline $\begin{array}{l}\text { Pre-test } \\
\text { vs. post- } \\
\text { test }\end{array}$ & 120.1 & $<0.001$ & 69.43 & $<0.001$ & 133.9 & $<0.001$ & 114.6 & $<0.001$ & 102.8 & $<0.001$ \\
\hline $\begin{array}{l}\text { Study I vs. } \\
\text { Study II }\end{array}$ & 0.004 & 0.950 & 0.012 & 0.914 & 0.141 & 0.708 & 0.002 & 0.967 & 2.38 & 0.128 \\
\hline $\begin{array}{l}\text { Interaction } \\
\text { effect }\end{array}$ & 2.32 & 0.132 & 16.96 & $<0.001$ & 13.56 & $<0.001$ & 1.19 & 0.279 & 6.42 & 0.014 \\
\hline
\end{tabular}

Table 3: Table 1. ANOVA Results for Pre-/Post-tests of SSRP and SSRP-NSRP

The learners certainly did better in their post-test than in the pre-test on all five measures, when both years are looked at together $(\mathrm{p}<0.001)$, as one would expect for any course of instruction. Differences between years on the other hand (with pre- and post-test not separated) is never significant. The crucial result, however, is the interaction effect, since this reflects whether the improvement between pre- and post-test was similar in both years or different (e.g. more marked in Study II than Study I). Indeed the interaction is significant for accent, fluency and grammar measures.

Looking now at each sub-skill separately in Figures 5 to 9, we can see clearly what the significance values are indicating. Figure 5 shows that learners' vocabulary use was better in the post-test than the pre-test in both years, as indeed I would hope for regardless of the type of role-play I used. The improvement seems slightly greater in Study II than Study I, but as the interaction effect is not significant $(\mathrm{p}=0.132)$, I cannot say definitively that SSRP-NSRP had a greater effect on vocabulary improvement (0.75) than SSRP did (0.57), but that both role-play methods led to a significant improvement over the course of the module as shown in Figure 5.

When we look at the pre-test and post-test mean scores for comprehension for SSRP and SSRP-NSRP learners in Table 1, the picture is somewhat similar to that for vocabulary. Pre-/post-test differences are as usual highly significant $(\mathrm{p}<0.001)$ while overall difference between years is not. Furthermore, improvements over the course of the module are similar in each year (Study I = 0.75 , Study II $=0.61$ ) (see Figure 6 ), so the interaction effect is not significant $(\mathrm{p}=0.279)$. Although Study I learners' comprehension scores for the pre-test were lower than those of Study II learners, their comprehension scores for the post-test were slightly higher than those of the Study II learners.

Figure 7 shows the results of pre-test and post-test mean scores for SSRP and SSRP-NSRP learners' accent. The learners in both years again did better in their post-test. However, in this instance the interaction effect is significant 
( $\mathrm{p}<0.001$ ), and we can see that this is due to the improvement with SSRP-NSRP in Study II being markedly greater (0.54) than that with SSRP in Study I (0.18) (see Figure 7), over the course of the module.

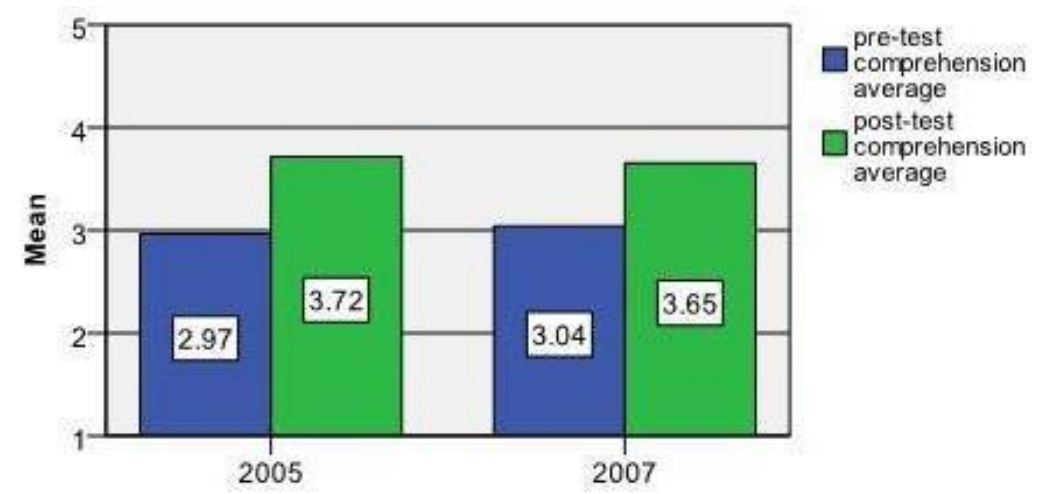

Figure 2: Fig. 6. Learners' Comprehension Skills

The learners' fluency in both years also improved in their post-test (Figure 8). The $p$-value $(\mathrm{p}<0.001)$ for the interaction effect between two years is again highly significant. Again, in Study II, learners' fluency (0.8) improved significantly more than in Study I (0.41) as shown in Figure 8.

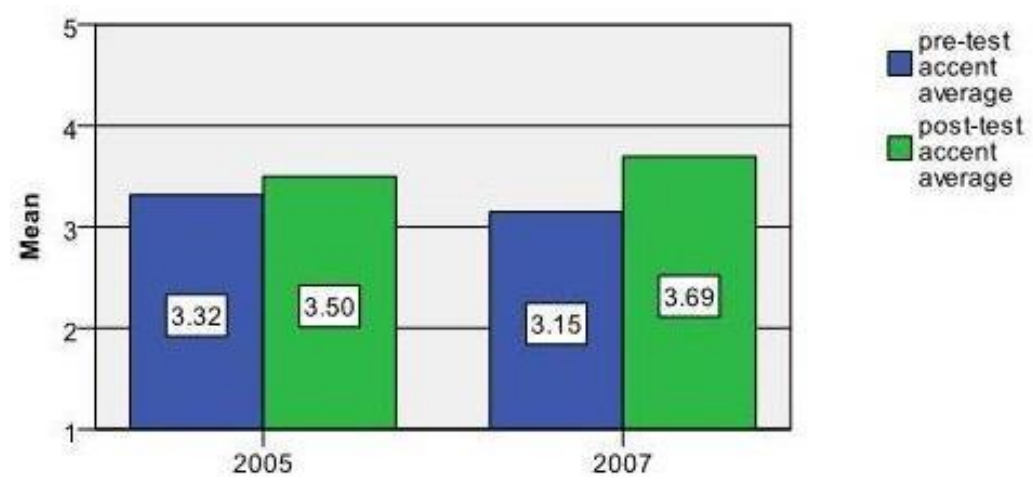

Figure 3: Fig. 7. Learners' Accent Skills

Finally, the grammar scores of post-test results were also better than in pre-tests in both years. But as for fluency and accent, the improvement was significantly greater in Study II than in Study I $(p=0.014)$ (Table 1). The learners' grammar scores in the pre-test did not show a big difference between years. But in their post-tests, Study II learners' grammar scores (improvement $=0.64$ ) were far higher than those of Study I learners (improvement $=0.38$ ) as shown in Figure 9. 


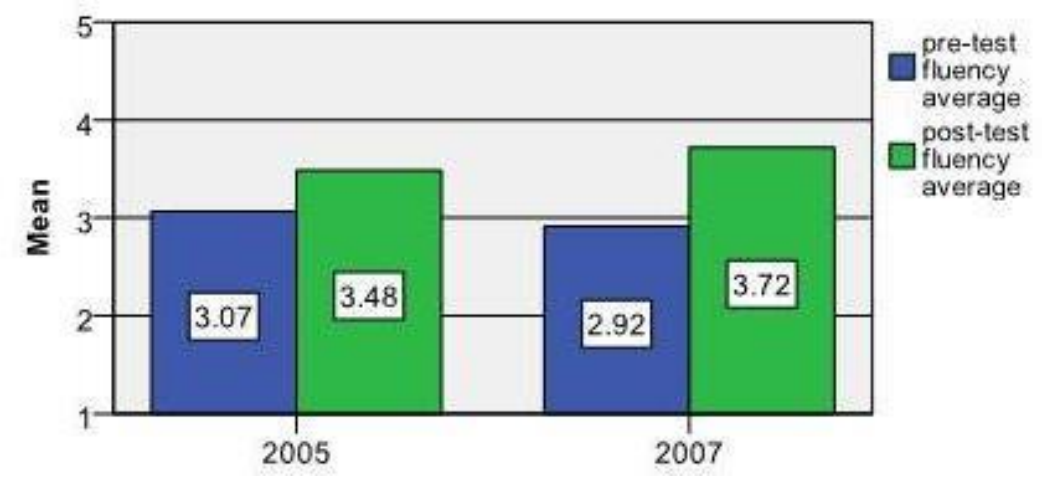

Figure 4: Fig. 8. Learners' Fluency Skills

\section{Discussion}

\subsection{Fluency}

The researcher was not surprised that differences were apparent between the learner groups concerning improvements in their fluency. Both SSRP and SSRP-NSRP activities provide learners with chances to practise speaking. However, it is no wonder that SSRP-NSRP learners' fluency was found to have improved more than that of SSRP learners since SSRP-NSRP learners simply had more chances to talk and thus talked more than SSRP learners in the class. Bygate (2001) investigated the effects of practising specific types of task using interview and narrative methods. In this study, Bygate asked learners both to perform the same task twice and also perform a new task of the same type. The results indicate that when performing the same task twice, learners manifested greater fluency and complexity; thus, it appeared that the opportunity to practise the same type of task twice was beneficial in developing speaking skills. Even though Bygate's study was not based on role-play activities, his results are similar to those of my study. In contrast with SSRP, SSRP-NSRP learners had more conversations with different people in each role-play class and they had to practise more. For instance, when one learner performed the role of a waiter, in SSRP-NSRP, he had 3 to 5 different customers and had to take an order 3 to 5 times. In this case, as he repeated his role as a waiter, his speaking should have become more fluent, if not also more competent with repeated mistakes reduced. More importantly, we can see why his fluency could have developed in that situation more than when he performed only one memorized script in SSRP.

\subsection{Grammar}

SSRP-NSRP learners' grammatical accuracy also improved more than that of SSRP learners. Even though I did not put a lot of emphasis on grammatical elements when preparing the learners for the role-play in each session, I still wanted to see if learners' knowledge of grammar would improve by performing 
SSRP and SSRP-NSRP activities, but did not expect the SSRP-NSRP learners' grammar would have improved significantly more than that of the SSRP learners. On reflection it is suggested that we interpret this result as follows: as with fluency, the SSRP-NSRP learners' grammatical knowledge could have developed because they were talking repeatedly with several different people.

In our case learners were not specifically instructed to focus on any one aspect of their language use, but there is evidence that is relevant to us from studies examining the Comprehensible Output Hypothesis (Swain 1995). Swain claims that in the process of interaction when a learner has received some negative input, the learner is pushed to use alternate means to get his or her message across. Thus, the process of achieving Comprehensible Output leads to more accurate production of the foreign language (Swain 1995: 248). Even though in our study we did not direct students to pay attention to grammar specifically in either Study I or Study II, and our preparation for role-play and feedback afterwards was the same, so cannot have had a direct effect, there are some ways in which students' attention may have been drawn to grammar more in Study II so that their grammatical knowledge improved.

First, in SSRP-NSRP, learners had a chance to correct their incorrect grammar as the more times one produces a grammatical error, the more chances there are for learners to notice it. In Bygate's (2001) study on the effects of task repetition on L2 oral language development, it was found that some form of task repetition can enable learners to shift their attention from the problem of conceptualization (i.e. thinking what message to convey) towards that of formulation (i.e. thinking of what words, grammar and pronunciation can express the message more correctly) (Levelt 1989). Bygate (2001: 17) indeed advocates that 'task recycling seems to provide the basis for learners to integrate their fluency, accuracy and complexity of formulation around what becomes a familiar conceptual base.' Multiple repetitions of a task such as those which occurred in Study II mean that some aspects of production (for example concerning content and what lexical choices are needed) become more automatised and there is therefore more mental capacity available progressively to attend to other aspects such as grammar. Thus, learners may become aware of grammatical errors which might have passed unnoticed the first couple of times due to the number of other things that there are to think about in speech. Second, there is a chance that an interlocutor may correct output or draw attention to it. Multiple repetitions also mean there are more opportunities for interlocutors to prompt awareness of errors and even supply corrections (though since it was beyond the scope of the present study I did not analyse the recordings of the role-plays, and therefore I cannot say for sure if this happened or indeed happened more in Study II than it did in Study I). In Study II, since learners performed a role several times, they had more chances to correct themselves or be corrected when they talked to different people within a similar (or sometimes the same) situation, and they might have used a similar or the same sentence. Therefore, SSRP-NSRP provided a useful stage for learners to practise their language skills and it was surely an effective way of 
developing learners' grammatical knowledge (i.e. accuracy not just fluency). A third reason might be as follows: learners were not just repeating the task more times in SSRP-NSRP, which may have had the effects described, but they were performing the task in a different way. Where a student memorises a script, as in SSRP, maybe when speaking he/she pays attention only to remembering the script. The learner does not generate the language in the usual meaning of processing speech (see Levelt's model of speaking 1989) as in real production. Hence if there is an error in the script the learner does not spot it as easily as when going through the normal process of speech production.

\subsection{Accent}

It is not surprising that SSRP-NSRP learners' accents improved more than SSRP learners' accents. It may seem logical to obtain this result since again SSRP-NSRP type role-play necessarily requires learners to practise speaking more than the SSRP type. SSRP learners also had to repeat the same words or sentences several times to memorize their dialogue. However, they were not told to consciously pay attention to their pronunciation or accent in particular, but they rather concentrated on memorizing each line (and might have done this mentally without speaking aloud). On the other hand, SSRP-NSRP learners did not need to memorize like SSRP learners did but they did more speaking and might have tried harder to make their partners ( 3 to 5 different people) understand, which means SSRP-NSRP learners might have paid more attention to accent or pronunciation while speaking, and indeed the same three arguments used in relation to grammatical knowledge above apply here again.

\subsection{Vocabulary and Comprehension}

SSRP-NSRP learners' vocabulary improved more than SSRP learners' skills, but not significantly. SSRP-NSRP learners' comprehension skills improved but not as much as SSRP learners did. It was expected that there could be a significant difference in vocabulary improvement between the two groups. The basis for this expectation was that SSRP-NSRP learners talked with different people and had different conversations in different situations with those people. Therefore, it was natural to assume that SSRP-NSRP learners might have used a wider range of vocabulary items or just different types of lexis than SSRP learners. However, the necessarily limited nature of the post-test role-play topic perhaps meant that both years' learners did equally well. Alternatively learners in the tests maybe did not make the situation complicated, or tried to avoid embarrassing situations so that neither of them would be stretched. In contrast to role-play activities in their normal class, during pre-/post-tests learners were very conscious of the need not to put their partner in a tricky situation. Therefore, we could not see a great difference between the two groups in terms of their vocabulary and comprehension skills. 


\section{Conclusion}

This action research which was primarily intended to improve my own teaching practice in the classroom not only brought about changes in my classroom, but also possibly offers new insights into learners' use of role-play in an EOP context. Both role-play types were surely successful in encouraging learners to communicate in pairs and to improve their communication skills in the target language. Hence I commend them for consideration by teachers and syllabus/textbook designers for any TE EOP module. However, each role-play has different features and may be useful in different contexts. For instance, SSRP might be appropriate for university entrants who have seldom had an English speaking class or have never studied tourism-related topics. For those learners, SSRP may encourage them to speak English and provide them with related background knowledge as indirect experience. In Vygotsky's (1978) terms this is a matter of supplying the right 'scaffolding' which helps students to connect prior knowledge, experience or learning with new information. On the other hand, SSRP-NSRP might be suitable for those who are more experienced in the tourism industry. Thus, when other EOP teachers attempt similar ideas in other universities with their learners who want to access the professional workplace, they could set up the type of role-play which is most suitable in the light of their learners' needs and experience.

\section{References -}

Al-Arishi, Ali Y. (1994): Role-play, real-play, and surreal-play in the ESOL classroom. In: ELT Journal 48/4, 337-346

Bygate, Martin (2001): Effects of task repetition on the structure and control of oral language. In: Bygate, Martin; Skehan, Peter; Swain, Merrill (eds.) Researching pedagogic tasks second language learning and testing. London: Longman, 23-48

Byrne, Donn (1986): Teaching oral English. London: Longman

Choi, Kyung-hee (2006): Needs analysis of students of Tourism English. In: The $10^{\text {th }}$ PAAL Japan Conference

Cunningsworth, Alan \& Horner, David (1985): The role of simulations in the development of communication strategies. In: System 13/3, 211128

Davies, Paul (1990): The use of drama in English language teaching. In: TESL Canada Journal 8/1, 87-99

Dickson, Patricia S. (1989): Acting French: drama techniques in the second language classroom. In: The French Review 63/2, 300-311 
Di Pietro, Robert J. (1982): The open-ended scenario: a new approach to conversation. In: TESOL Quarterly 16/1, 15-42

Dörnyei, Zoltan \& Thurrell, Sarah (1994): Teaching conversational skills intensively: course content and rationale. In: ELT Journal 48/1, 40-49

Harper-Whalen, Susan \&Morris, Sandra (2005): Using a role-play activity in training. In: Training Solutions 9, 1-4

Holden, Susan (1981): Drama in language teaching. London: Spottiswoode Ballantyne Ltd.

Korean Tourism Organization (KTO). Retrieved June 2012 from http: // english.visitkorea.or.kr/enu/index.kto.

Levelt, Willem J. M. (1989): Speaking: from intention to articulation. Cambridge, Mass.: MIT Press

Littlewood, William (1981): Communicative language teaching: an introduction. Cambridge: Cambridge University Press

Livingstone, Carol (1983): Role play in language learning. Singapore: London: Longman

Magos, Kostas \& Politi, Fotini (2008): The creative second language lesson: the contribution of the role-play technique to the teaching of a second language in immigrant classes. In: RELC 39/1, 96-112

Maley, Alan \& Duff, Alan (1982): Drama techniques in language learning. Cambridge: Cambridge University Press

Maley, Alan (1987): Role play. Oxford: Oxford University Press

Min, Chang-kee (2009): A study on internationalization of Tourism English education. English Language Teaching 21/2, 311-331

McDonough, Jo (1984): ESP in perspective: a practical guide. London: Collins ELT

McDonough, Jo \& Shaw, Christopher (1993): Materials and methods in ELT: a teacher's guide. Oxford: Blackwell

Pi-Chong, Su (1990): The effectiveness of role-play activities in learning English as a foreign language by Chinese college students. Ph.D. thesis, University of San Francisco

Seong, Myung-hee (2001): Tourism English teaching and learning model: Focused on the improvement of oral communication skills. Ph.D. Thesis, Korea University 
Siskin, Jay H. \& Spinelli, Emily (1987): Achieving communicative competence through gambits and routines. In: Foreign Language Annals 20/5, $393-401$

Stern, Susan L. (1980): Drama in second language learning from a psycholinguistic perspective. In: Language Learning 30/1, 77-97

Sturtridge, Gill (1977): Using simulation in teaching English for specific purposes. In: Holden, Susan (ed.) English for Specific Purposes. Modern English Publication, 32-34

Swain, Merrill (1995): Three functions of output in second language learning. In: Cook, Guy \& Seidhofer, Barbara (eds.) Principles and practices in applied linguistics: Studies in honor of H. G. Widdowson. Oxford: Oxford University Press, 125-144

Tompkins, Patricia K. (1998): Role playing/simulation. The Internet TESL Journal 4/8 http://iteslj.org/Techniques/Tompkins-RolePlaying. html [last accessed August 7, 2015]

Van Ments, Morry (1983): The effective use of role-play. London: Kogan Page

Vygotsky, Lev S. (1978): Mind in society. Cambridge: Harvard University Press 